\title{
Spastic paraparesis, cerebellar ataxia, and intention tremor: a severe variant of FXTAS?
}

\author{
S Jacquemont, A Orrico, L Galli, P K Sahota, J A Brunberg, C Anichini, M Leehey, S Schaeffer, \\ R J Hagerman, P J Hagerman, F Tassone
}

J Med Genet 2005;42:e14 (http://www.jmedgenet.com/cgi/content/full/42/2/el4). doi: 10.1136/jmg.2004.024190

$\mathrm{F}$ ragile $\mathrm{X}$ associated tremor/ataxia syndrome (FXTAS) is a recently identified neurodegenerative disorder affecting older adult males with pre-mutation alleles of the fragile $\mathrm{X}$ mental retardation 1 (FMRl) gene. ${ }^{1-3}$ These male carriers, in their fifties and older, develop progressive intention tremor, cerebellar ataxia, progressive cognitive difficulties, and variable features including peripheral neuropathy, lower limb proximal muscle weakness, and autonomic dysfunction.

Radiological signs include global brain atrophy and white matter disease characterised by hyperintensities in the middle cerebellar peduncles (MCP) on T2 sequence with scattered periventricular disease, corresponding to spongiform changes and demyelination on neuropathological studies. $^{2}$

Here we report three pre-mutation carriers (two sisters and one sporadic case) presenting with spastic paraparesis, cerebellar ataxia, and intention tremor, and having neuroimaging features suggestive of a severe variant of FXTAS. A random $X$ inactivation pattern was found in the two affected sisters. The third female sibling was unaffected and her inactivation pattern was significantly skewed. This suggests that the $\mathrm{X}$ inactivation ratio may be responsible for the incomplete penetrance of the neurological symptoms in this family.

\section{CASE DESCRIPTIONS}

\section{Case 1 (II-2)}

The first sister developed spasticity and balance difficulty in the third decade of her life. During this time, she underwent neurological evaluation. She was well oriented, with intact speech and cognitive function. Examination of the lower extremity showed paraparesis, mild spasticity, and positive Babinski. The upper extremities showed diminished coordination and intention tremor. EEG, ECG fundoscopy, electromyography (EMG), and nerve conduction studies were normal. Cerebrospinal fluid (CSF) was normal, with absence of oligoclonal bands. Muscle biopsy showed a chronic neurogenic process. She had anxiety and mild depression.

\section{Case $2($ (II-3)}

The other sister gradually developed spasticity with dragging of the toes while walking, lower limb weakness, and difficulty with balance. Neurological evaluation at 35 years of age showed normal cognitive functions. Examination of the lower extremities, showed paraparesis, mild spasticity, positive Babinski, extensor plantar responses, mild muscle wasting, pes cavus, hammer toes, acrocyanosis, and loss of proprioception and vibratory sensation from the knees downwards. Gait was wide based and uncoordinated, with hyperextension of the knees. The upper extremities had mild incoordination and intention tremor. EEG, ECG, fundoscopy EMG, and nerve conduction studies were normal. CSF was normal, with no oligoclonal bands. Motor evoked potentials showed abnormal central motor conduction especially in the right limb. Muscle biopsy was abnormal, demonstrating a

\section{Key points}

- Fragile X associated tremor/ataxia syndrome (FXTAS) is a recently identified neurodegenerative disorder affecting older adult males with pre-mutation alleles of the fragile $X$ mental retardation 1 (FMR 1) gene.

- Carriers evelop progressive intention tremor, cerebellar ataxia, progressive cognitive difficulties, and variable features including peripheral neuropathy, lower limb proximal muscle weakness, and autonomic dysfunction.

- We report two sisters and an unrelated man with FXTAS, and detail their MRI findings and results from molecular studies.

mild neurogenic process. Spasticity increased, requiring the use of a walker and, subsequently a wheelchair. She was found to be anxious and presented a mild hearing loss. Both sisters (case 1 and case 2 ) had been clinically diagnosed as having hereditary spinocerebellar syndrome. The third sister (II-1) has not developed neurological disease.

Molecular investigations excluded triplet expansion in the SCA1, SCA2, SCA3, SCA6 SCA7, and Friedreich ataxia genes in both the affected sisters. Exclusion of the SPG7 (16q24.3) and SPG5 (8pl2-q13) locus was determined by informative markers.

\section{Case 3}

Case 3 is a 69 year old male pre-mutation carrier, the grandfather of a fragile $X$ child. He experienced an onset of walking difficulties, fatigue, and toe dragging in his midfifties. The neurological evaluation at that time showed lower limb spasticity, hyper-reflexia, extensor plantar responses, muscle wasting without fasciculations, and distal loss of sensation. Motor evoked potentials showed slight increase in conduction latency and a lack of response by cortical stimulation. EMG showed a mildly neurogenic response. Testing for infectious and autoimmune aetiology was negative. He was subsequently clinically diagnosed as having spastic paraparesis. By 65 years of age, he needed a cane and wheelchair, suffered almost daily falls, and developed urinary incontinence, dysphagia, and resting tremor. Vertical downward saccades were abnormal. Nerve conduction velocity studies demonstrated mildly decreased sensory conduction in the lower extremities.

\section{RESULTS}

Magnetic resonance imaging

All three cases demonstrated increased T2 signal intensity in the middle cerebellar peduncles and the adjacent deep white matter of the cerebellar hemispheres (table 1; fig 2). The 


\begin{tabular}{|c|c|c|c|}
\hline & $\begin{array}{l}\text { Cases } 1 \\
\text { and } 2\end{array}$ & Case 3 & $\begin{array}{l}\text { "Typical" } \\
\text { FXTAS" }\end{array}$ \\
\hline \multicolumn{4}{|l|}{ Clinical presentation } \\
\hline Spastic paraparesis & + & + & - \\
\hline Cerebellar ataxia & + & + & + \\
\hline Intention tremor & + & - & + \\
\hline Neuropathy & + & + & \\
\hline Onset (age in years) & 30 & 50 & $50-70$ \\
\hline \multirow{2}{*}{\multicolumn{4}{|c|}{$\begin{array}{l}\text { MRI findings: increased T2 signal } \\
\text { intensity }\end{array}$}} \\
\hline & & & \\
\hline Middle cerebellar peduncles & + & + & + \\
\hline $\begin{array}{l}\text { Cerebellar white matter } \\
\text { Subependymal and deep white }\end{array}$ & & + & \\
\hline $\begin{array}{l}\text { matter of frontal and parietal lobes } \\
\text { Medial lemniscus and corticospinal }\end{array}$ & + & + & + \\
\hline tract & + & + & - \\
\hline Cerebellar volume loss & + & + & + \\
\hline
\end{tabular}

pattern seen in case 3 is more typical of the alteration described in the MR images of FXTAS subjects, although there can be variability, and some patients have no imaging alteration. ${ }^{2}$ In our three cases, increased intensity was also found symmetrically throughout the pons, appearing to reflect involvement of transverse pontine fibres and the corticospinal tract. Furthermore, in all three cases, subependymal and deep white matter increased T2 signal intensity was demonstrated in the frontal and parietal lobes, and all patients also demonstrated mild to moderate cerebral cortical, cerebellar hemisphere, and vermis volume loss (fig 2).

Molecular studies

DNA studies revealed that all three sisters in family 1 were carriers of the fragile $\mathrm{X}$ pre-mutation (fig 1). The allele sizes,

\section{A}

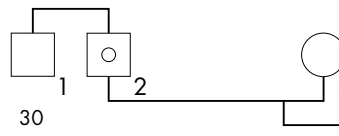

30 3
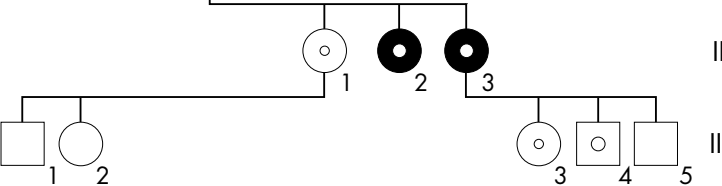

B

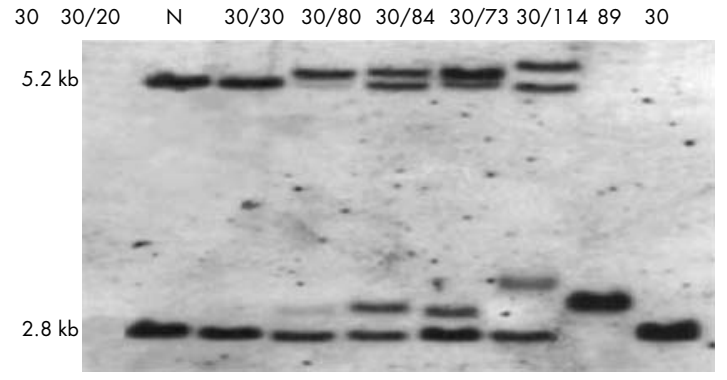

Figure 1 (A) Pedigree from case 1 (II-2) and 2 (II-3). Allele size (CGG repeats) are shown above part $B$. (B) Southern blot analysis. DNA isolated from peripheral blood leucocytes. Hybridisation was performed using probeA STB 12.3 and digested with EcoR1. Details of the methods are described in Tassone et al. ${ }^{4}$ Pre-mutation bands are visible in all three sisters (II- 1 , II-2, II-3). In the two affected sisters (II-2, II-3), the activation ratio is random $(A R=0.5)$. In the unaffected sister $(I I-1)$, the pre-mutation allele is barely visible $(A R=0.9)$. The normal methylated band $(5.2 \mathrm{~kb})$ and normal unmethylated band $(2.8 \mathrm{~kb})$ band are indicated. NC, normal control. measured by PCR analysis, were of 80/30, 84/30, and 73/30 CGG repeats in II-1, II-2, and II-3 respectively. However, the activation ratio (AR) values were $0.9,0.5$, and 0.5 respectively in II-1, II-2, and II-3, showing a random inactivation in cases 1 and 2 (II-2 and II-3) rather than the skewed inactivation ratio in II- 1 . ( $\mathrm{AR}=1$ indicates a normal allele active in $100 \%$ of the cells, while an $\mathrm{AR}=0$ indicates that the normal allele is always carried on the inactive $\mathrm{X}$ chromosome). Because their mother (I-3) is a carrier of normal alleles $(30,30)$, all sisters inherited the pre-mutation from their father (I-2). III-3 and III-4 (32 and 30 years old respectively) were asymptomatic and were found to be carriers of a premutation allele ( 114 and 89 CGG repeats respectively) (fig 1).

In peripheral blood leucocytes of all the pre-mutation carriers, relFMRI messenger RNA levels were significantly elevated, consistent with previous findings. ${ }^{567}$ The mean (SEM) FMRI mRNA levels were $4.5(0.79)$ for III-4, 5.78 (0.54) for III-3, and 2.0 (0.20) for II-3. II-2 was not available for FMRI testing. Normal levels of FMRI mRNA were observed in I-3 $(1.36(0.18))$ and III-5 (1.60 (16)), both carrying normal alleles, and in II-1 (1.42 (0.03)), the asymptomatic sister who carries a pre-mutation allele.
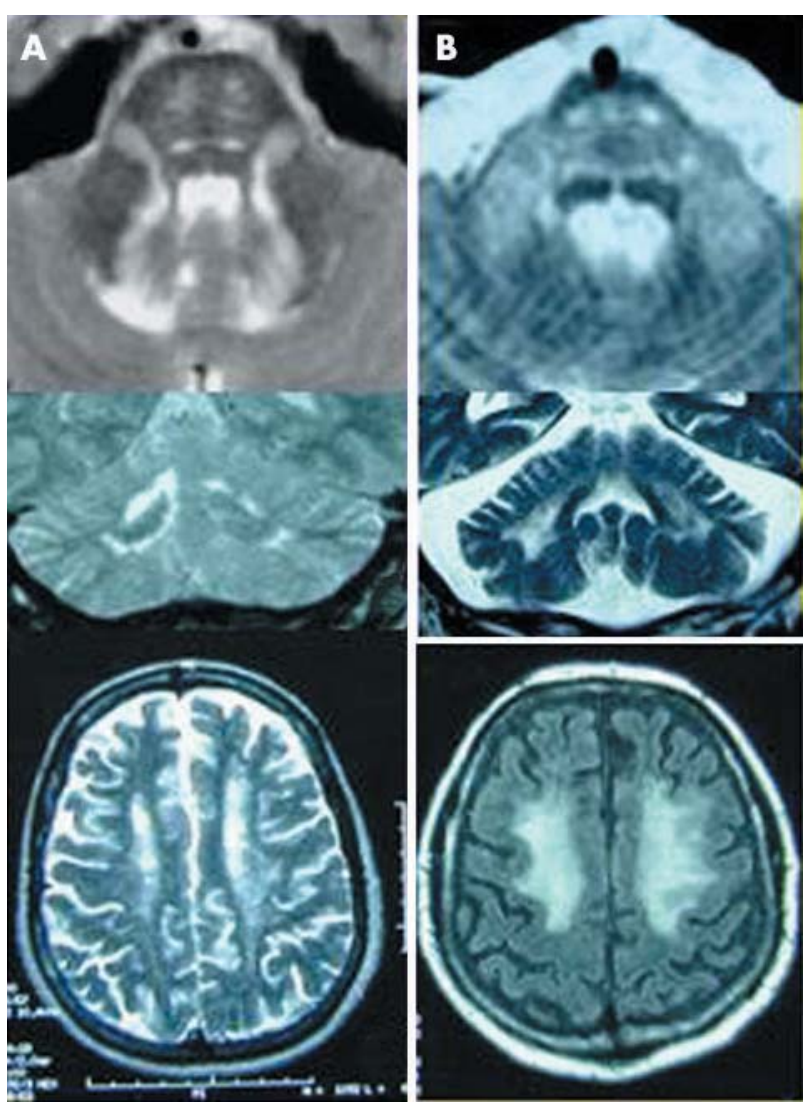

Figure 2 (A) MR images from case 1 and 2. In cases 1 and 2, the increased T2 signal intensity was noted to involve the middle cerebellar peduncles in a more ventral and medial distribution ( $A$, top) than in case 3 (B, top). (A) Top, T2 weighted image showing brain stem and MCP increased T2 signal intensity in case 1; middle, coronal T2 weighted image showing partial involvement of deep white matter of the cerebellum in case 2; bottom, T2 weighted axial image showing increased signal intensity in cerebral white matter and cortical volume loss in case 2. (B) MR images from case 3. Top, T2 weighted image showing increased signal intensity in the brain stem and MCP; middle, coronal T2 weighted image showing involvement of the deep white matter of the cerebellum; bottom, FLAIR transverse image showing increased signal intensity in the cerebral white matter and cortical volume loss. 
Molecular testing was not carried out in our laboratory for case 3 .

\section{DISCUSSION}

Here, we report on one male and two female carriers of the fragile $\mathrm{X}$ pre-mutation, who all initially presented with isolated spastic paraparesis and the subsequent development of other symptoms previously described in FXTAS. ${ }^{1}$ Several genes involved in the pathogenesis of spastic paraparesis and spinocerebellar ataxia were excluded in cases 1 and 2 . Multiple sclerosis and infectious or autoimmune aetiologies were excluded in all cases. We therefore suggest that spastic paraparesis can be a clinical presentation in severe cases of FXTAS.

As detailed by Brunberg et al, ${ }^{2}$ bilateral increased T2 signal intensity in the middle cerebellar peduncles and adjacent deep cerebellar white matter is characteristic of FXTAS, but it can be observed in several clinical entities including multiple system atrophy and Wilson's disease (which was ruled out in case 3). Similar findings are not features of spinocerebellar ataxias or hereditary spastic paraplegia. ${ }^{7-10}$ The MRI of case 3 is typical of the imaging characteristics previously described in FXTAS. Case 1 and case 2 presented with a less diffuse increase in $\mathrm{T} 2$ signal intensity in the middle cerebellar peduncles, although other findings were similar (fig 2, table 1). Increased T2 signal intensity in the pons of all three subjects most probably reflects neurone loss and gliosis involving pontine nuclei and transverse pontine fibres crossing to reach the middle cerebellar peduncles. In contrast to a recently reported series of eight patients with pyramidal, cerebellar, and dorsal column symptoms presenting in the first or second decade, the subjects of this report did not have altered T2 signal intensity in the posterior limb of the internal capsule, the thalamus, the splenium of the corpus callosum, or the peripheral white matter of the cerebellum. ${ }^{11}$ The later age of presentation, the defined pre-mutation carrier state, and the pattern of MRI alteration are all within the pattern of variability consistent with correlates of FXTAS.

Cases 1 and 2 presented some discrepancies (such as an earlier onset and spastic paraparesis) from the classic presentation of FXTAS. ${ }^{1}$ However, they also presented with cerebellar ataxia and intention tremor, which are the two major clinical criteria of FXTAS. ${ }^{1}$ Such early onset of neurological symptoms in a pre-mutation carrier is rare, but has previously been reported by Macpherson et $a l^{12}$ and Hagerman et al. ${ }^{13}$ Case 3 initially presented with isolated spastic paraparesis and subsequently developed typical symptoms (both clinical and on neuroimaging) of FXTAS. It is possible that a modifying gene is acting synergistically with the FMRI pre-mutation allele in order to produce this variant form of FXTAS.

Two of the three cases presented here are women. So far, we have observed fewer cases of FXTAS in women. Hagerman et al $^{13}$ reported five women with typical clinical and neuroimaging presentation of FXTAS except that cognitive deficits were not present. One of these demonstrated the classical eosinophilic intranuclear neuronal and astrocytic inclusions of FXTAS. ${ }^{12}$ This lower penetrance in women is compatible with an X linked disorder in which the penetrance only reaches $30 \%$ overall in male carriers. ${ }^{14}$

FXTAS is a recently described neurodegenerative disorder with an unusual age related low penetrance. ${ }^{1}$ Atypical forms of FXTAS are to be expected with earlier onsets and additional clinical features.

It is important to note that the two symptomatic sisters (cases 1 and 2), carriers of the fragile $X$ pre-mutation, have an unaffected sister (II-1). The unaffected sister is also a carrier but demonstrates a skewed activation ratio $(\mathrm{AR}=$ 0.9 ), meaning that in $90 \%$ of her cells the pre-mutation allele is inactive. In comparison, the $\mathrm{AR}$ is random in the two affected sisters ( $A R=0.5$ in both). It is possible that the AR in neuronal cells and in peripheral blood leukocytes is different. However, we have recently observed similar AR values in both brain and blood tissues derived from two female carriers of the fragile $\mathrm{X}$ pre-mutation (unpublished data).

Although, generally, women show only moderate pathogenic consequences of the FMRI pre-mutation (such as premature ovarian failure), neuronal and astrocytic intranuclear inclusions have been observed in one female carrier of the pre-mutation who had FXTAS. ${ }^{13}$ We have observed female carriers of the fragile $X$ pre-mutation who were affected with FXTAS. ${ }^{13}$ Their clinical presentation is similar to what has been reported in men; however, they have not demonstrated significant cognitive deficit. Penetrance appears to be much lower in women. ${ }^{14}$

\section{ACKNOWLEDGEMENTS}

We would like to thank all of the members of the family participating in this study, and Dr Pareison and Dr Savoiardo for the clinical and MRI information. This study was supported in part by a grants from the National Institute of Neurological Disorders and Stroke (NS 43532, PJH), and by general support from the UC Davis MIND Institute.

\section{Authors' affiliations}

S Jacquemont, R J Hagerman, MIND Institute, University of California Davis Medical Center, Sacramento, CA, USA

A Orrico, L Galli, Molecular Medicine, Azienda Ospedaliera Universitaria Senese, Siena, Italy

P K Sahota, P J Hagerman, F Tassone, Department of Biochemistry and Molecular Medicine, School of Medicine, University of California Davis, Davis, CA, USA

J A Brunberg, Department of Radiology, School of Medicine, UC Davis Medical Center, Sacramento, CA, USA

C Anichini, Department of Pediatrics, University of Siena, Siena, Italy M Leehey, Department of Neurology, University of Colorado Health

Science Center, CO, USA

S Schaeffer, Service de Neurologie, Centre Hospitalier Universitaire de Caen, France

Competing interests: none declared

Correspondence to: Dr F Tassone, UC Davis, Medicine, Biochemistry and Molecular Medicine, One Shields Avenue, Davis, CA 95616, USA; ftassone@ucdavis.edu

Received 17 June 2004

Revised 27 July 2004

Accepted 25 August 2004

\section{REFERENCE}

1 Jacquemont S, Hagerman RJ, Leehey M, Grigsby J, Zhang L, Brunberg JA, Greco C, Des Portes V, Jardini T, Levine R, Berry-Kravis E, Brown WT, Schaeffer S, Kissel J, Tassone F, Hagerman PJ. Fragile x premutation tremor/ ataxia syndrome: molecular, clinical, and neuroimaging correlates. Am J Hum Genet 2003;72:869-78.

2 Brunberg JA, Jacquemont S, Hagerman RJ, Berry-Kravis EM, Grigsby J, Leehey MA, Tassone F, Brown WT, Greco CM, Hagerman PJ. Fragile X premutation carriers: characteristic MR imaging findings of adult male patients with progressive cerebellar and cognitive dysfunction. Am J Neuroradiol 2002;23:1757-66.

3 Hagerman RJ, Leehey M, Heinrichs W, Tassone F, Wilson R, Hills J, Grigsby J, Gage B, Hagerman PJ. Intention tremor, parkinsonism, and generalized brain atrophy in male carriers of fragile X. Neurology 2001;57:127-30.

4 Tassone F, Hagerman RJ, Arocena DG, Khandjian EW, Greco CM, Hagerman PJ. Intranuclear inclusions in fragile $\mathrm{X}$-associated tremor/ataxia syndrome (FXTAS) neural cells with premutation alleles. J Med Genet 2004;41:e43.

5 Tassone F, Hagerman RJ, Taylor AK, Gane LW, Godfrey TE, Hagerman PJ. Elevated levels of FMR1 mRNA in carrier males: a new mechanism of involvement in the fragile-X syndrome. Am J Hum Genet 2000;66:6-15.

6 Tassone F, Hagerman RJ, Chamberlain WD, Hagerman PJ. Transcription of the FMR 1 gene in individuals with fragile $X$ syndrome. Am J Med Genet 2000;97:195-203. 
7 Cambi F, Tartaglino L, Lublin F, McCarren D. X-linked pure familial spastic paraparesis. Characterization of a large kindred with magnetic resonance imaging studies. Arch Neurol 1995;52:665-9.

8 Durr A, Brice A, Serdaru M, Rancurel G, Derouesne C, Lyon-Caen O, Agid Y, Fontaine B. The phenotype of "pure" autosomal dominant spastic paraplegia. Neurology 1994:44:1274-7.

9 Ormerod IE, Harding AE, Miller DH, Johnson G, MacManus D, du Boulay EP, Kendall BE, Moseley IF, McDonald WIMagnetic resonance imaging in degenerative ataxic disorders. J Neurol Neurosurg Psychiatry 1994;57:51-7.

10 Krabbe K, Nielsen JE, Fallentin E, Fenger K, Herning M. MRI of autosomal dominant pure spastic paraplegia. Neuroradiology 1997;39:724-7.

11 van der Knaap MS, van der Voorn P, Barkhof F, Van Coster R, KragelohMann I, Feigenbaum A, Blaser S, Vles JS, Rieckmann P, Pouwels PJ. A new leukoencephalopathy with brainstem and spinal cord involvement and high lactate. Ann Neurol 2003;53:252-8.

12 Macpherson J, Waghorn A, Hammans S, Jacobs P. Observation of an excess of fragile-X premutations in a population of males referred with spinocerebellar ataxia. Hum Genet 2003;112:619-20.

13 Hagerman RJ, Leavit BR, Farzin F, et al. Fragile X-associated tremor/ataxia syndrome (FXTAS) in females with the FMRI premutation. Am J Hum Genet In press.

14 Jacquemont S, Hagerman RJ, Leehey MA, Hall DA, Levine RA, Brunberg JA, Zhang L, Jardini T, Gane LW, Harris SW, Herman K, Grigsby J, Greco CM, Berry-Kravis E, Tassone F, Hagerman PJ. Penetrance of the fragile Xassociated tremor/ataxia syndrome (FXTAS) in a premutation carrier population: Initial results from a California family-based study. JAMA 2004;291:460-9 